\title{
Math students help their community develop balanced refuse collection routes
}

Sean Andris, Department of Mathematics, Kutztown University, Kutztown, Pennsylvania, USA, seanandris33@gmail.com

Brian Bailey, Public Works Superintendent, Kutztown Borough, Kutztown, Pennsylvania, USA, bbailey@kutztownboro.org

Joe Ritzko, Department of Mathematics, Kutztown University, Kutztown, Pennsylvania, USA, joeritzko@gmail.com

Francis J. Vasko, Department of Mathematics, Kutztown University, Kutztown, Pennsylvania, USA, vasko@kutztown.edu

\section{Abstract}

In fall of 2017, the Superintendent of Public Works for Kutztown Borough approached Kutztown University's Department of Mathematics seeking help in "re-balancing" refuse collection routes in the Borough of Kutztown. Historically (for many decades), refuse was collected two days a week on the south side (Mondays and Thursdays) of Main Street and two days a week on the north side (Tuesdays and Fridays) of Main Street. Wednesdays were used for recycling collection. Over the years, new housing development was primarily on the north side of Main Street. As a result of this development, refuse collection time had become "unbalanced"; requiring more time for the north side collection. During the spring semester 2018, several math majors in their last semester at Kutztown University developed a new refuse collection strategy. This strategy balanced collection times over the four collection days and just as importantly, minimized the modifications to the existing routes. Additionally, a minimum number of residents were impacted while accounting for future housing development. Their strategy has been successfully used in the Borough of Kutztown since August 2018.

Keywords: waste collection vehicle routing problem, operational research, undergraduate student projects.

\section{Introduction}

Kutztown is a borough in Berks County, Pennsylvania, USA, with a population of about 5000 inhabitants. For many decades, refuse collection was performed on Mondays and Thursdays for residents living on the south side of Main Street. Residents on the north side of Main Street had their refuse collected on Tuesdays and Fridays. Recycling is collected on Wednesdays for the entire borough. Over the years, new housing development has been primarily on the north side of Main Street. This has resulted in it taking longer to collect refuse on the north side of Main Street.

The Superintendent of Public Works for the Borough of Kutztown approached the Kutztown University (KU) Department of Mathematics toward the end of the 2017 fall semester. He was seeking KU's help in "re-balancing" Kutztown Borough's refuse collection routes. A primary goal of the re-balancing was to have each refuse collection day be approximately equal in terms of time needed to complete the refuse collection. A second major goal was to modify the existing routes as little as possible. A third goal was to impact as few residents as possible. It is important to note that the Public Works Department of the Borough of Kutztown felt that the existing refuse collection routes, subject to the constraint that south side collections were not mixed with north side collections, had been continually improved and fine-tuned over the years and were reasonably optimized.

In the next section we will briefly review the literature of vehicle routing for refuse collection. This will be followed by the solution approach and recommendation made by the $\mathrm{KU}$ math students. 
Subsequently, we will discuss the implementation process of their recommendation and the educational benefits of this project for the students.

\section{Approaches in the literature for refuse collection vehicle routing problem}

Although the vehicle routing problem literature is quite extensive, the literature on vehicle routing applied specifically to refuse collection is quite limited. A small number of specific examples include Benjamin and Beasley (2010) who discuss a meta-heuristic for waste collection using multiple vehicles that takes into account customer time windows and driver rest periods. Buhrkal et al. (2012) use a large neighbourhood search to solve the waste collection vehicle routing problem with customer time windows. Malakahmad et al. (2014) use a Tabu search approach that optimizes waste collection routes to reduce route lengths and collection time. Finally, a paper by Wy et al. (2012) discusses a garbage collection problem dealing with construction sites and shopping districts that involves the use of huge containers.

\section{A strategy for re-balancing refuse collection}

\subsection{Background}

Based on the Public Works request, the professor of the two undergraduate operations research courses (OR) (MAT361 and MAT362) approached three students who had taken these courses as juniors and were already registered for their final semester at KU (Spring 2018). Although all three students had a full semester of courses, they were willing to register for two credits of independent study during which time they would study the refuse re-balancing problem and hopefully develop a solution strategy. Their professor, having several decades of industrial experience, was not optimistic that the students would be able to develop a practical solution approach to the problem in the limited time period of one semester - a little more than three months. He certainly did not expect that, if the students developed a practical solution strategy to re-balance refuse collection, that it would necessarily be implemented by Kutztown Borough. Remember that the current refuse collection routes had basically been used for several decades and the need for re-balancing the routes had been recognized for years, but no alternatives had been implemented to solve the problem. What chance did three undergraduate students with no former knowledge of the problem have to solve this problem in three months? However, the OR professor felt that, even if the students did not solve the problem, exposing the three students to a real-world problem provided them the opportunity to interact with real-world "clients" - both management and workers. This interaction would be helpful in further developing the students' modelling and interpersonal skills.

\subsection{Student solution approach}

The OR professor stressed to his students that they needed to get familiar and thoroughly understand the real-world problem before they could expect to solve it. To that end, the students were interested in doing a "ride along" during refuse collection in order to get first-hand knowledge of the process. Unfortunately, for several reasons, this was not possible. The students needed to try to understand and solve the refuse re-balancing problem by studying a street map of Kutztown Borough (see appendix) and asking questions of the Public Works Superintendent. Typically, the refuse collection crew were not directly available for questions due to time constraints. The key aspect of the problem that the students focused on was the need to re-balance the collection days. Simply using Main Street as a dividing line was no longer a viable alternative, but how were they to better balance the collection routes with minimal disruption to the existing routes? Additionally, the students soon learned that even trying to obtain collection time data would be time consuming and not a straightforward task. 
Given all the constraints of the problem, the students decided on the following strategy. They would develop a number of scenarios in which, during the south side refuse collection route, when the truck was at Main Street, it would cross over to the north side and do a limited amount of refuse collection and then return to the cross over location and continue with the south side collection as usual. Although not a very sophisticated approach, it appeared to be the best strategy for balancing the collection times with minimal disruption. The problem was to determine the best crossover location and which north side streets to collect during the crossover. After considering several options, the students determined that the best crossovers would be at either the west end of the borough or the east end of the borough. The reason for these two choices was that by including one of the ends of the north side collection with the south side collection, disruption to the north side route would be minimized. In contrast, if the collection truck, during the south side collection, crossed Main Street in the middle of the borough, there would be a "gap" in the north side collection route.

Since new housing development was taking place at the northeast section of the borough, it made sense to include the refuse collection for the northeast end of the borough with the south side collection route. After discussions with the Public Works Superintendent, it was decided that the recommendation would be that during the south side collection route, when the truck was close to the intersection of Main Street and Elm Street, the truck would cross to the north side of Main Street and collect refuse at the east end of the borough. This would include the new housing development on Seem Drive (see map of Kutztown Borough in the appendix). The collective opinion of the group was that this modified collection strategy would, on average, reduce the north side collection time by about 30 minutes and add 30 minutes to the south side route. Thus, considerably improving the balance between collection times of the new "south side" route and the new "north side" route while minimizing disruptions to the existing routes.

\section{Implementing the recommended strategy for re-balancing refuse collection}

The students' recommendation (discussed in the previous section) was accepted by the Public Works Superintendent of the Borough of Kutztown at the end of April 2018. However, the Public Works Superintendent wanted the students to present their re-balancing strategy to the refuse collection crew for their reaction and, hopefully, approval. At the beginning of May 2018 (right before the end of the spring 2018 semester), the students, their OR professor, and the Public Works Superintendent met with the head of the refuse collection crew who had been on the job for several decades. After the students explained their proposed strategy for re-balancing refuse collection, the crew head expressed concern as to what degree the proposed strategy would actually re-balance the collection routes. After additional discussion in which the students addressed his concerns, the refuse collection crew head felt that the proposed strategy was worth a try. Next, in early June, this recommendation was presented and accepted by the Public Works Committee. Later in June, this recommendation was accepted by Kutztown Borough Council. The new routes were implemented in August 2018 and are being used currently by the Borough of Kutztown.

In an email communication (dated November 15, 2018) between the Borough of Kutztown and KU, the Public Works Superintendent stated that "Overall I am happy so far with changing the route....Depending on how the last areas of town that can be developed are developed we may have to revisit this again at some point down the road. For now this has given me what I was looking for. A more balanced route and less involvement by the public works guys to help the refuse guys."

\section{Educational benefits and final thoughts}

In their two undergraduate OR courses, the students had worked on group projects in which they solved complex (scaled-down) real-world problems involving strategic planning, both single-period and multi-period production planning and inventory problems, distribution and location problems and 
multi-period personnel requirements planning problems. However, in all these cases the professor was the "client" that the students needed to interact with when modelling and solving the problem. The refuse collection re-balancing project afforded the students the unique opportunity to see what was required to get their solution approach actually implemented in the real-world by interacting with real-world clients-both workers and managers.

The OR professor was very pleased with how his students appropriately confronted, solved and were successful at getting their strategy implemented especially given the short time that the students had to work on the problem. This project was certainly a very positive aspect of interview discussions that the students had for industrial OR positions.

\section{Appendix}

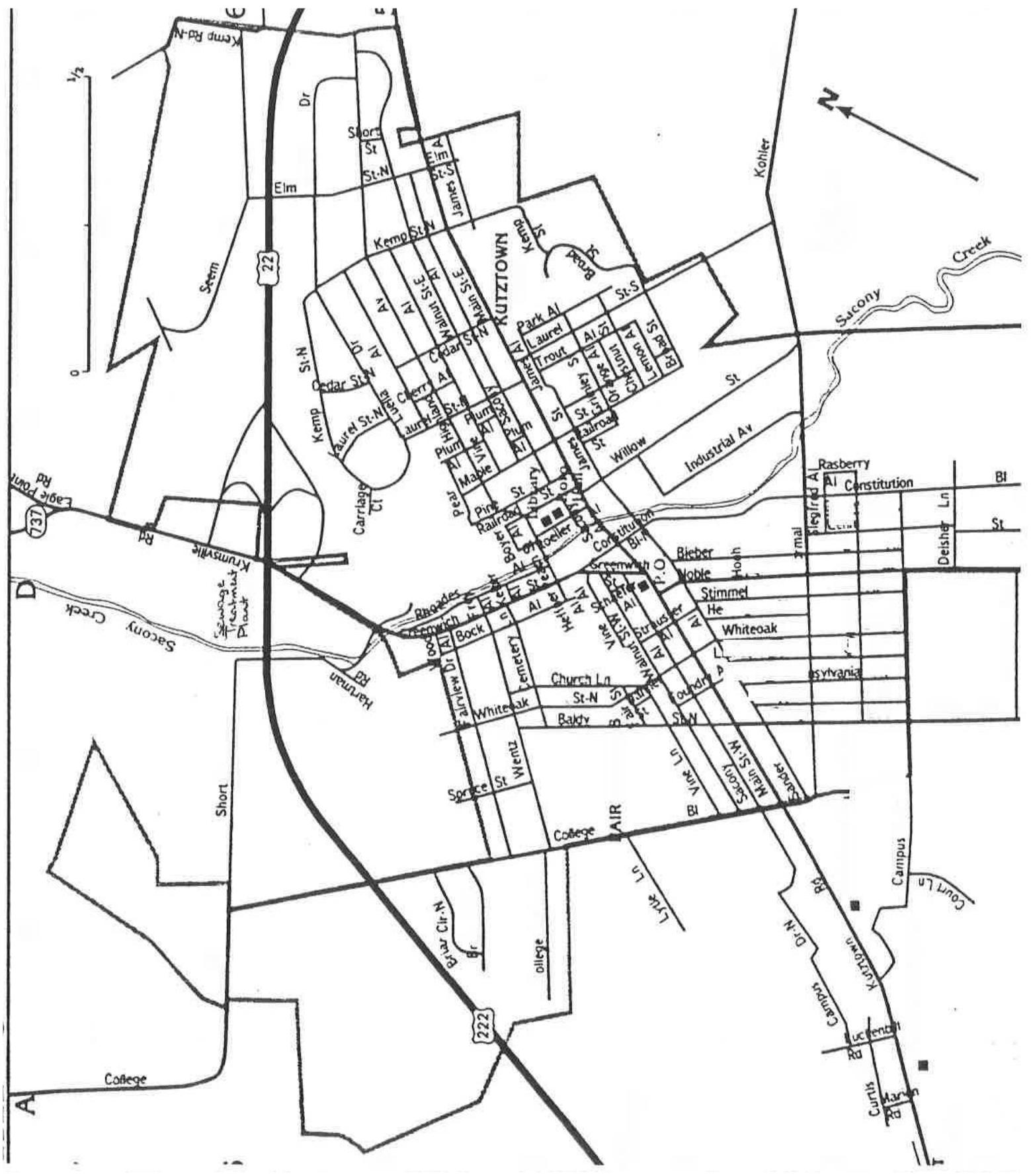

Figure: Map of Kutztown Borough 


\section{References}

Benjamin, A. M., and Beasley, J. E., 2010. Metaheuristics for the Waste Collection Vehicle Routing Problem with Time Windows, Driver Rest Period and Multiple Disposal Facilities. Computers \& Operations Research, vol. 37, no. 12, pp.2270-2280., doi:10.1016/j.cor.2010.03.019.

Buhrkal, K., Larsen, A., and Ropke, S., 2012. The Waste Collection Vehicle Routing Problem with Time Windows in a City Logistics Context. Procedia - Social and Behavioral Sciences, vol. 39, pp.241-254, doi:10.1016/j.sbspro.2012.03.105.

Malakahmad, A., Md Bakri, P., Md Mokhtar, M.R., and Khalil, N., 2014. Solid Waste Collection Routes Optimization via GIS Techniques in Ipoh City, Malaysia. Procedia Engineering, vol. 77, pp.20-27, doi:10.1016/j.proeng.2014.07.023.

Wy, J., Kim, B-I., and Kim, S., 2013. The Rollon-Rolloff Waste Collection Vehicle Routing Problem with Time Windows. European Journal of Operational Research, vol. 224, no. 3, pp.466-476, doi:10.1016/j.ejor.2012.09.001. 